\title{
Evaluation of Curriculum Localization Approach in Master's Degree of Curriculum Planning Filed Based on Klein Model
}

\section{Evaluación del enfoque de localización del plan de estudios en la maestría en planificación del plan de estudios presentada según el modelo de Klein}

Yadolah Esfandiyari

Shahed University, Tehran, Iran

ORCID: https://orcid.org/0000-0001-7425-5741

Soolmaz Nourabadi*

Shahed University, Tehran, Iran.

ORCID: https://orcid.org/0000-0002-9292-8011

Received 06-14-20 Revised 08-10-20 Accepted 09-01-20 On line 09-30-20

*Correspondence

Email: nourabadi@shahed.ac.ir
Cite as:

\footnotetext{
Esfandiyari, Y., \& Nourabadi, S. (2020). Evaluation of Curriculum Localization Approach in Master's Degree of Curriculum Planning Filed Based on Klein Model. Propósitos y Representaciones, 8 (SPE3), e772. Doi: http://dx.doi.org/10.20511/pyr2020.v8nSPE3.772
} 


\section{Summary}

In recent years, the evolution plan in the educational system and curriculum has been one of the most important topics in educational circles. This implies that the programs implemented in higher educational system have not been fully achieved for various reasons. One of the most important reasons is "not paying attention to the localization approach in the curriculum". Curriculum planning is one of the interdisciplines that can play an important role in influencing the curriculum process of humanities. However, the lack of a suitable native curriculum model has made it increasingly dependent on foreign sources and plenty of used terms are imported and translated, resulting in little attention to customs, culture, social, economic and political conditions of society. Although our culture and civilization derive from the most complete and highest order of divine teaching, the educational system has failed to provide an appropriate educational model that is appropriate to cultural conditions throughout the country. The present study has evaluated localization approach of Master's Degree in Curriculum Planning from the viewpoints of faculty members of public universities in Tehran in 2017-2018 academic year. To achieve the research purpose, the main question is "How is desirable of consideration the curriculum localization approach in curriculum planning field based on nine elements of Klein"? This research is descriptive-survey research. The questionnaire has been used for data collection. The statistical population of this study consists faculty members of educational sciences field and have been used Krejcie and Morgan sampling method. Descriptive and inferential statistical methods were used for data analysis. The results of evaluated elements showed that faculty members of Tehran state university ranked elements learning activities, teaching methods, time, materials and resources, grouping, place, and evaluation at a relatively desirable level and target and content elements as undesirable level.

Keywords: Evaluation, Localization Approach, Curriculum, Higher Education, Klein Model.

\section{Resumen}

En los últimos años, el plan de evolución en el sistema educativo y el currículo ha sido uno de los temas más importantes en los círculos educativos. Esto implica que los programas implementados en el sistema educativo superior no se han logrado en su totalidad por diversas razones. Una de las razones más importantes es "no prestar atención al enfoque de localización en el plan de estudios". La planificación del plan de estudios es una de las interdisciplinas que puede desempeñar un papel importante al influir en el proceso del plan de estudios de humanidades. Sin embargo, la falta de un modelo curricular nativo adecuado lo ha hecho cada vez más dependiente de fuentes extranjeras y muchos términos usados se importan y traducen, lo que resulta en poca atención a las costumbres, la cultura, las condiciones sociales, económicas y políticas de la sociedad. Aunque nuestra cultura y civilización derivan del más completo y más alto orden de enseñanza divina, el sistema educativo no ha logrado proporcionar un modelo educativo apropiado que sea apropiado a las condiciones culturales en todo el país. El presente estudio ha evaluado el enfoque de localización de la Maestría en Planificación Curricular desde los puntos de vista de los profesores de las universidades públicas de Teherán en el año académico 2017-2018. Para lograr el propósito de la investigación, la pregunta principal es "¿Cómo es deseable considerar el enfoque de localización curricular en el campo de la planificación curricular basado en nueve elementos de Klein"? Esta investigación es una investigación de encuesta descriptiva. El cuestionario se ha utilizado para la recopilación de datos. La población estadística de este estudio está compuesta por profesores del campo de las ciencias de la educación y se ha utilizado el método de muestreo de Krejcie y Morgan. Se utilizaron métodos estadísticos descriptivos e inferenciales para el análisis de datos. Los resultados de los elementos evaluados mostraron que los miembros de la facultad de la universidad estatal de Teherán clasificaron los elementos actividades de aprendizaje, métodos de enseñanza, tiempo, materiales y recursos, agrupación, lugar y evaluación en un nivel relativamente deseable y los elementos de destino y contenido como niveles indeseables. 
Palabras clave: Evaluación, Enfoque de Localización, Currículo, Educación Superior, Modelo de Klein.

\section{Introducción}

Undoubtedly, curricula at universities and higher education institutions play a key and decisive role in the success or failure of these institutions. To be clear, the curriculum mirrors the whole view of progress and reflects the responsiveness of universities to the changing needs of society. Given the tremendous innovations and changes taking place in different fields, the mission of documenting findings and disseminating and promoting them in form of well-organized and structured curricula is the responsibility of the universities. Unfortunately, despite the importance of curricula in higher educational institutions, their attention is insufficient, and even the effort required to review, evaluate, modify, and correct them is not on the agenda (Fathi Vajargah, 2007). It should be known that academic curriculum is very sensitive, delicate and complex process. Dealing with academic curriculum requires that specialists be sensitive to sciences in which the project is to be implemented; also be aware of the potentials, capabilities, interests, and priorities of students for whom the curriculum is designed; know the knowledge and developments of field in question and identify the resources and facilities at their disposal; and have ability and practical knowledge to research, teach and evaluate. Therefore, that model of curriculum planning in higher education will be successful if it is present among the participants in curriculum process (Fathi Vajjargah, 2006).

In the meantime, the evaluation of higher educational programs is very important problem that should be regularly and scientifically implemented in all academic disciplines. Evaluation is obviously integral part of any educational activity, whether planning or execution. Therefore, most of adjusted curricula have not been evaluated. Even change in some curricula without proper evaluation of that curriculum is often supervised by one or more instructors (Azizi, 2000). The necessity of evaluation in higher education is because of

1. Evaluation of educational systems is one of the dynamic requirements of these systems. In other words, the lack of continuous evaluation process in educational systems causes them to stagnate.

2. The quality of education and research is one of concerns that academic systems always strive to achieve. Continuous improvement of quality of higher education requires use of evaluation (Mohammadi et al., 2007). The most important objective of evaluation in higher education is to improve, guarantee, and improve academic quality (Bazargan, 1997). Because of educational course while codification of curriculum may be perfectly tailored to individual and social needs, but as time passes and technological changes, especially changing needs of economic and social sectors, cultural change has lost its proportion. Thus, by evaluating the curricula, it can be identified to fit the needs and expectations of individual and society (Bazargan, 1996).

The goals of the academic curriculum are obtained on the base of study of culture, higher education functions, social services and curriculum (Seraji et al., 2007) and curricula are the most important component of any country's higher educational system. Paying attention to goals and missions of the Ministry of Science, Research and Technology show that some of them include: deepening and expanding sciences, knowledge, human and Islamic values and enhancing the artistic and aesthetic manifestations of the scientific and heritage of Iranian and Islamic civilization, providing specialized human resources and development of human resources in the country, active participation in the process of policymaking of educational system and development of human resources in order to establish the necessary coordination between the programs of different levels of education of country as well as to contribute to 
promotion of Islamic culture, ethics and spirituality in academic community of society (Goals law, Duties, and Organizations of Ministry of Science, Approved 2004-8-29). That this reflects the attention of policymakers in the field of education to localization of curriculum. Therefore, to achieve these goals, there is a need to examine the presence or absence of localization approach in curriculum of universities and higher educational centers in order to explain present status and plan to achieve the desired status.

Discussions and criticisms of new foundations of modern science, identity and social identity following the phenomenon of globalization by various scholars have led to emergence of newer concepts such as "Indigenous Knowledge" and "Localization". Nowadays, indigenous knowledge and localization approach of knowledge are completely different and have many degrees and severity and weakness. Indigenous knowledge, according to experts, is the knowledge that has been developed and disseminated by different people in the local community over time, and obviously this knowledge is based on different foundations in different communities. So the knowledge that is valid and valuable to them, may not be useful to other societies, and it would not even be surprised if local knowledge system in different societies differs from one another. Cheng believes that if the strength of indigenous knowledge is significant, it can contribute to growth and development of nations as well as growth and development of global knowledge, and this knowledge can be credible in other societies. The opposite is also possible. For example, if indigenous knowledge is affected by external elements, it is natural that it will not have the necessary dynamics and development, and consequence will be that indigenous knowledge becomes immersed in global knowledge and becomes ineffective and it is clear that the reason is inadequacy of indigenous knowledge itself (Cheng, 2004).

Evaluation is needed to understand the current state of localization approach of curriculum and is an important element of curriculum evaluation. Evaluation is one of the most important and sensitive components of curriculum process. The sensitivity and importance of evaluation in curriculum are that no human activity, especially those of complexity and sophistication, can be established without qualitative review and improvement. Only through evaluation of different stages of curriculum can efficiency and effectiveness of curricula be increased (Momeni Mahmoui, 2009). Given the importance of curriculum for higher educationan policymakers and its sensitivity and complexity, and emphasis on evolving curriculum localization in the face of globalization and its consequences as well as the capacities, interests, and priorities of Iranian students and their religious beliefs and cultural values. So curriculam should be devised that consciously uses patterns and methods of others and adapts them to conditions of indigenous community in addition to updating and reinforcing indigenous methods, or linking alien knowledge with indigenous knowledge and conditions, led to their comprehensive development that has been announced in document of change in academic curriculum to all Iranian universities in recent years. Therefore, in order to identify the actual state of affairs and identify the extent to which the objectives of curriculum, strategies and executive policies related to objectives and consequently, operational planning and forecasting of resources and costs are appropriately and reasonably determined and also to assess compliance results with stated goals, problem analysis and identification of bottlenecks and their causes and therefore suggesting corrective actions, doing research seems necessary.

Different models and templates have been proposed for curriculum design, such as Assure model, Akker model, Eisner model, Klein model, and Indiana model. The present study deals with evaluation of localization approach of curriculum of Master degree in curriculum planning field in Tehran Universities; and Francis Klein model has been used which includes nine elements: Objectives, Content, Teaching- Learning Strategies, Educational Resources, Learning activities, Time, Learning space, grouping, Evaluation methods. This model is the most famous and complete classifications that offered in curriculum elements. In view of 
theories' process of educational experts about elements of curriculum, the above-mentioned elements are more comprehensive, pointing to more variables in curriculum (Fathi Vajjargah, 2013) that due to the sensitivity, elegance, and complexity of cademic curriculum is a good model for academic curriculum evaluation and review. Considering the above, the present study intends to examine and evaluate the curriculum approach of Master degree in curriculum planning based on the Klein model, from the perspective of professors and faculty members. Therefore, this study will evaluate this problem: What is the desirability of a localization approach in curriculum of master's in curriculum planning? What is the current state of attention to localization approach of curriculum in the field of curriculum planning? And how far is it from the ideal situation?

\section{Research Questions:}

1) To what extent is the desirability of considering the localization approach in determining the Goals of curriculum planning approved by faculty members?

2) How desirable is consideration of localization approach in curriculum Content formulation from the perspective of faculty members?

3) How desirable is consideration of localization approach in curriculum Learning Activities element from the perspective of faculty members?

4) How desirable is consideration of localization approach in element of Teaching-Learning Strategies of curriculum from the perspective of faculty members?

5) What is the desirability of considering localization approach in the Time element of curriculum from the faculty's point of view?

6) How desirable is consideration of localization approach in Educational Resources element of curriculum field from the perspective of faculty members?

7) How desirable is to consider localization approach in Grouping element of curriculum from the faculty perspective?

8) How good is localization approach in Space element of curriculum from the faculty's point of view?

9) How desirable is to consider localization approach in Evaluation element of curriculum from the perspective of faculty members?

\section{Research method}

The research method is descriptive-survey. The statistical population of the study consists of professors of curriculum field in public universities of Tehran in the academic year of 2017-2018. The total number of male professors is 31 from Al-Zahra University, Tehran, Kharazmi, Shahed, Shahid Beheshti and Allameh Tabatabai; who answered the questionnaire in a total of 30 faculty members. Also, female professors of curriculumn field in public universities of Tehran in the academic year 2017-2018, which are 23 people from the mentioned universities, which in total 20 faculty members answered the questionnaire. The sampling method is available sample method. In the present study, a researcher-made questionnaire with five-point Likert scale were used for data collection, and the T-test with SPSS 20 software was used to analyze the collected data. 


\section{Findings}

This study have used a model presented by Francis Klein in the curriculum. This model considers the 9 elements of curriculum that is a holistic approach to curriculum. Since the existence of these nine elements is essential in any curriculum and thinking about them constitutes curriculum, they should be considered in localization approach of curriculum. These elements represent dimensions of curriculum that curriculum designers deal with in curriculum design. Therefore, in this study, the researchers intend to identify the present curriculum in accordance with local needs and to identify current curriculum according to needs of faculty members of Tehran universities regarding the existing curriculum as well as identify and adapt the present curriculum to suit indigenous needs.

In order to answer the first question of the research, 5 criteria were considered for professors and evaluated by their viewpoints about them. In general, the result of this factor was undesirable for both groups, indicating that goals element is far from desired level of localization approach. In explaining this finding, it can be said that there are insufficient coherence and coordination between the objectives of credits with overall objectives of curriculum field and fundamental development document. Also objectives of headings are not sufficiently indigenous and expected skills and attitudes are expected. After the course, the student's mind is not fertilized with his/her culture and society; and also the goals of field are not in line with the student's indigenous interests and the mission of localizing curriculum and are not commensurate with needs of labor market and development of practical skills required of indigenous specialists. It is, therefore, necessary to reconsider the objectives of this field.

To answer the second question of the research, 4 criteria for evaluation of content element were selected from the viewpoint of male and female professors. The overall result of this question has been evaluated poorly by educational science professors, which means that attention to localization approach in content factor is lower than the desirable level and quality. In explaining these results, it can be said that the content of lessons did not provide students with the basic and specialized concepts required by students or that content was not of necessary diversity to meet needs and interests of students. It can also be pointed out that the content of field does not sufficiently prepare students for necessary skills and competence in the field for local community labor market. Even this content does not conform to current and indigenous scientific theories and findings. According to this explanation of modification and correction, this factor is necessary to achieve the desired level.

In the third question of the study, the status and overall outcome of learning activities element was relatively desirable according to the four criteria set by male professors' group and was undesirable by female professors' group. This level of evaluation may indicate that the master's degree lessons titles in curriculum field do not address the students' indigenous aptitude for determining and adjusting their learning activities and their scientific and indigenous abilities, and more importantly, their individual or collective learning activities not been in line the goals of localization mentioned field. Finally it can be concluded that content of lessons does not adequately address the needs and interests of the students. Given that the amount of attention to localization approach in curriculum learning activities is relatively desirable and far from optimal curriculum studies, more attention to learning activities in localization approach of curriculum seems to be necessary.

In the fourth research question, the status and overall outcome of teaching-learning strategies of curriculum element of curriculum field has been also evaluated according to average score for male professors at relatively desirable level and for female professors at undesirable level. The point is that the degree of attention to localization approach of element of teaching activities in this field is relatively desirable and far from optimal status and level. This finding also suggests that some professors who have advanced teaching methods are not interested in localization approach of curriculum and have used traditional teaching methods 
during the teaching-learning process. New learning strategies such as problem-solving, research, group activities have rarely been used that emphasize localization approaches.

In order to answer the fifth research question, that is the status and overall outcome of curriculum time element of the curriculum field, 2 criteria were selected for evaluating desired factor and overall result of this factor has been evaluated by male professors at relatively desirable level and by female professors at a poor level. This means that attention to time element in localization approach of curriculum is lower than desirability and quality. This finding also suggests that day-to-day classes may not be appropriate to indigenous conditions or that the time allocated to educational courses may not be appropriate to thisconditions.

To answer the sixth research question, 5 criteria for evaluation of curriculum material and source elements of curriculum planning field were selected for two groups. Results have obtained from this evaluation show that the attention to localization approach of this element is relatively favorable for male professors and undesirable for female professors, which is far from desirable. Discussion of this finding may indicate that teaching process did not utilize instructional resources and materials appropriate to localization approach of curriculum. Also curriculum in this field does not provide diverse educational media tailored to student's indigenous characteristics. In addition, educational and audiovisual facilities and equipment are not used in accordance with localization approach of curriculum. While the use of resources and teaching aids makes learning faster, more effective, and more sustainable for learners. Lack of adequate information resources such as the Internet, books, and magazines at university is evident to students. Also, reliable and up-to-date scientific resources may not be sufficiently utilized. As a result, this element needs to be taken into account in localization approach in curriculum field.

In the seventh question, the status and overall outcome of curriculum grouping element of curriculum field is also results obtained from evaluation criteria in this factor from the viewpoint of male professors at a relatively desirable level and from viewpoint of female professors at an undesirable level. This indicates that attention to localization approach of grouping element in curriculum field is well below the desired level. In explaining this finding, it can also be said that in process of teaching and learning lessons, the formation of indigenous active problem-solving groups of students for collective research with an indigenous approach has not been established, or for enhancing students' scientific and specialized knowledge, partnership, collaboration and a coherent group discussion (question and answer) is not created by indigenous approach, and ultimately it is not important to identify and divide different learning assignments (projects) between students with indigenous approach.

To answer the eighth question, two criteria for evaluation of space element were selected for two groups and for male professors it has been evaluated at a relatively desirable level and for female professors at an undesirable level. This means that attention to element of space in localization approach of curriculum is far from desirable. Discussion of this finding also suggests that standard location may not be provided in terms of light, breadth, and comfort in accordance with localization approach, and given different course contents of this field is not used of different locations such as schools and library and eventually standard location may not be used in terms of practical and group activities appropriate to localization approach of curriculum area and may require measures to improve element's attention in localization approach of curriculum.

In order to answer the ninth research question, 5 criteria for evaluation of curriculum evaluation method element were selected for both groups. And the overall result of this element has been evaluated at a relatively desirable level by the male professors and at the undesirable level by the female professors, which means that localization approach in evaluation element is lower quality and desirable. This finding also suggests that localization approach was not taken into account in regulation of content of evaluation of academic achievement and that professors 
of education did not consider localization approach in use of various types of academic progress. Also, the final evaluation and feedback have not been explicitly addressed, or even evaluation results are not used to measure the practical desirability of goals and content of curriculum with localization approach, and perhaps necessary feedback from evaluation results in order to revision is not given due to localization approach. Therefore, a quick review of evaluation element in localization approach of curriculum field is essential.

\section{Conclusiones}

Given that the purpose of this study is to evaluate curricula of curriculum field from the perspective of faculty members of educational sciences. The results of this study showed that the curriculum of this field is based on Francis Klein's nine elements of "learning activities, teaching-learning strategies, time, space, material and source, grouping and evaluation" were evaluated by professors at a relatively desirable level, but the two "goals and content" elements were evaluated at an undesirable level. Whereas if there is to be a change in curriculum of an academic field, these two elements are more important and influential than the other elements that should be set in the curriculum formulation in the first place, goals are identified based on upstream documents that place great emphasis on localization approach. And secondly, the content of lessons is tailored to goals that emphasize localization approach so that other curriculum elements are influenced by these two important elements. Therefore, these criteria are at disadvantage to the desired level, and modifications to curriculum field are necessary to achieve the desired level of localization approach.

Overall, academic curriculum is particular sensitivity, fineness, and complexity, and with addition of localization approach of curriculum. This sensitivity and complexity are doubled, as the university must pay special attention to the localization approach of curriculum and, on the other hand, is essential that Iranian university can compete with the world's universities and therefore must be up-to-date. In fact, the university, in order to achieve allround growth and development, must use its own models and methods and adapt it to indigenous conditions of society, update its curricula and link foreign knowledge with with its indigenous approaches. In this case, the task becomes more complex and sensitive.

In the third millennium, countless challenges such as rapid growth of globalization and collapse of communication boundaries, spread of information technology, global information exchanges, economic growth of knowledge and research, growing demand for global development and national and international competition are reasons of constant and fundamental changes in educational systems. Accordingly, policymakers and officials seek to reform educational systems, especially higher education, to prepare future leaders to meet challenges of new age. Faced with this vibrant and full of motive environment, if curricula outlined in each country's development programs do not consider its national and indigenous values and frameworks as sturdy tree roots in depth of belief and acceptance of its nextgeneration, it is surely in this turbulent path are confused and may forget about their social and cultural identity in the process of globalization. Therefore, education at a particularly high level has expanded to include all aspects of people's lives, either directly or indirectly, and has changed the social, economic, cultural and political life of people. Therefore, it is important to know perspectives outlined in development programs and upstream documents in educational programs and to pay attention to goals outlined in educational programs. Considering that from perspective of Islamic Republic of Iran, in 2025, Iran should be the first hub of education in the region, and also with regard to emphasis on localization in various sciences, and in particular in higher education, attention to aspects of globalization as well as the need for localization in education, especially higher education, are aspects that should not be overlooked or overshadowed by one another. 
According to researchers of this study, it is necessary to enhance indigenous knowledge and to benefit from global knowledge in order to preserve national identity, by refining that part of global knowledge that is inconsistent with our religious beliefs and cultures and in some cases is a threat. Let's turn these threats into opportunities with tact and intelligence. Iran, which has a very rich civilization background, needs to do its utmost to maintain cultural and national traditions in face of challenges of globalization. This will not be possible unless with design of academic curriculum that, while thinks global, pays special attention to localization approach and seeks to extend its indigenous knowledge in context of globalization.

\section{Referencias}

Bazargan, Abbas (1996). Applying Evaluation of Education to Improve the Quality of Higher Education with Emphasis on Medical Education Ministry of Health and Medical Education. Secretariat for Supervision, Evaluation, and Development of Tehran University of Medical Sciences.

Bazargan, Abbas (1997). Quality and Evaluation in Higher Education: A Look at National and International Experiences. Proceedings of First Seminar on Higher Education in Iran. First volume. Tehran: Allameh Tabatabai University Press.

Seraji, Farhad et al. (2007). Virtual University Curriculum Design. Journal of Curriculum Studies. 2 (6). Pp: 79-95.

Azizi, Nematollah (2000). The Concept of Quality and its Improvement Systems in Education. Education Quarterly. 61. Pp: 23-43.

Fathi Vajargah, Kuroush (2006). Curriculum Planning and Curriculum Development in Higher Education. Tehran: Kuroush Institute Press Publication.

Fathi Vajargah, Kuroush (2007). Principles of Curriculum Planning. Eighth Edition. Tehran: Iran Zamin Publications.

Fathi wajargah, Kuroush (2013). What is the curriculum? (Concepts, and limits of curriculum as a specialty). Tehran: Mehrban Publications.

Mohammadi, M., Naseri Jahromi, R., Moeini Shahraki, H., and Mehrabanian, N. (2013). Internal Effectiveness and External Effectiveness of Medical Professional Doctoral Curriculum from the Perspectives of Students, Graduates and Faculty Members of Yazd Shahid Sadoughi University of Medical Sciences. Iranian Journal of Medical Education. (3). 233-243.

Hossein, Momeni Mahmui (2009). Evaluation of curriculum in higher education. Journal of Medical Education Development and Development Center of Baqiyatallah University of Medical Sciences. (2).

Ministry of Science, Research and Technology (2004). Law of Purposes, Duties, and Organizations of the Ministry of Science Approved 29 - 8 - 2004.

Cheng, Y. C. (2004). Fostering local knowledge and human development globalization of Education. International Jornal of Management. 18 (1). 7-24 